established. Other more recent manipulation techniques include the provision of artificial nesting sites, which is helping the bald ibis in Turkey; the reduction of competition for nest sites to favour species such as the cahow; the elimination of introduced predators, a method used extensively in New Zealand; supplemental feeding, which hopefully will stop the decline in the California condor; fostering by similar species, e.g. whooping cranes being successfully introduced into sandhill crane nests; and removal of populations to safer areas, as was done with the seven remaining New Zealand black robins taken to a nearby island.

This is an essential reference work for anyone involved in conservation of threatened birds.

TIM INSKIPP

\title{
Reptiles of Northern and Central Europe, by Donald Street. Batsford,
} $£ 10$.

Until fairly recent years the reptiles and amphibians of Europe were not well covered in English natural history books. Now such books appear with increasing frequency, and this one follows hard on the heels of the excellent Collins Field Guide published last year, reflecting the increasing interest in herpetology among naturalists - although the trend seems to have reached the academic zoological establishment!

The present book gives a clear and readable account of the different species, some 25 in all, of lizards, snakes and chelonians which inhabit northern and central Europe. The information covers external appearance, food, reproduction, behaviour, general habits, habitats and distribution; there are, unfortunately, no distribution maps. A useful introduction deals in a very general way with reptilian biology, including such topics as relationship with man, snake-bite and its treatment, and the care of captive animals. It is perhaps a pity that the author did not spread his net a little wider and discuss some of the very interesting physiological studies on thermoregulation and other topics made in recent years. There is, however, a good bibliography of publications dealing with the more traditional areas of natural history and an appendix on the reptiles of southern Europe.

Well illustrated and produced, it will be an attractive addition to the library of anyone interested in the herptiles of Europe, despite its somewhat restricted scope.

A. d'A. BEILIAIRS

\section{Brief Reviews}

Greenshanks (Poyser, Berkhamsted, Herts, $£ 8.80$ ), by Desmond and Maimie NethersoleThompson, is much more than a revision of Desmond's 28-year-old New Naturalist classic. It represents a full lifetime's work on his favourite bird by our top ornithological monographer, helped by his daughter (and in various ways by the rest of his large family). A first-class book of its kind.

Wildfowl of the World (Blandford Press, Poole, Dorset, $£ 7.50$ ), by Eric Soothill and Peter Whitehead, is welcome as a fine collection of colour photographs of ducks, geese and swans, although unfortunately not complete. The text describes the birds, their behaviour, habitat, distribution, food, voice, display and breeding habits, in a compendious way. Buy it for its photographs.

The Birds of Zanzibar and Pemba, by R.H.W. Pakenham (British Ornithologists' Union, c/o I,ondon Zoo, $£ 4.00$, air mail $£ 5.30$ ), is the second in the BOU's excellent series of checklists. The first was for I.ibya. These two islands are little known or visited nowadays, and this excellent conspectus of their avifauna will be valuable when, as is hoped, tourism restarts, and will give ornithologists something to work on. 